\title{
Economic Cooperation and Regional Stability in East Asia: Perspective from China
}

\author{
Dai Changzheng
}

Published online: 27 September 2013

(C) CEEUN 2013

\begin{abstract}
With the drastic change and contrast of international strength after the 2008 financial crisis, there emerges new features of economic cooperation in east Asia, two of which have far-reaching impacts on the region's stability and development: First, America is expanding its engagement in Asian affairs and attempting to lead East Asian affairs with its advocation of TPP and the multilateral system under the Asia-Pacific Cooperation mechanism advocated and led by the United States poses tremendous challenges to the growing cooperation mechanisms in East Asia. Second, East Asian countries and China are economically more and more interdependent on each other, meanwhile, these countries have growing concerns over China's political and military strength. So they have close economic ties with China but cooperate with America on security issues, which will be an outstanding trend in the next decade. For China, the two above mentioned trends involve some of China's diplomatic priorities: China-US relation and its relations with neighboring countries, thus making China's surrounding environment more sensitive and complicated and strategically posing a severe threat to its general goal of peaceful rise. The competition over the leadership of economic cooperation in East Asia and the possible spillover effect of divergent interests and lack of strategic trust in this area may add to the uncertainties in regional stability. All these have forced China to reconsider its strategic choice in East Asia. This thesis suggests that in terms of strategic choices of the form of East Asian cooperation, China should transform China-US relation from "strategic competition" into "strategic coordination". While deepening functional cooperation in economic areas, China needs to focus on conducting strategic dialogues with major East Asian countries to enhance their strategic trust.
\end{abstract}

D. Changzheng $(\bowtie)$

School of International Relations, University of International Business and Economics (UIBE), Beijing, People's Republic of China e-mail: daicz@126.com 
Keywords Economic cooperation in East Asia · Leadership of cooperation ·

Balancing powers

\section{Strategic Coordination}

With the drastic change and contrast of international strength after the 2008 financial crisis, new features of economic cooperation in East Asia emerge, which stem from the specific condition of regional cooperation in East Asia and are closely related to the competition over the leadership of this region among several powers. All of these factors have contributed to the complexity of the overall cooperation environment in this region, exerted profound influences on regional stability and development and brought more challenges to the Chinese government's decisions on regional cooperation policies.

\section{New Features of Economic Cooperation in East Asia}

\section{TPP and America's "Returning to Asia”}

There are many economic cooperation mechanisms in East Asia with overlapping functions and diversified memberships, including mechanisms inside East Asia, subregional and even inter-regional mechanisms. After the development of a decade, economic cooperation mechanisms in East Asia have evolved into a "concentric circle" regional cooperation framework characterized by openness, flexibility, diversification and coexistence with ASEAN as the leadership, "10+1" as the foundation, " $10+3$ " at its core as the main channel and East Asia Summit as the necessary supplement.

However, another mode of Asia-Pacific cooperation- TPP, Trans-Pacific Partnership (or the Trans-Pacific Strategic Economic Partnership Agreement), has come to the fore with US support in recent years. In 2010, TPP became the focus of the 18th APEC Economic Leaders Meeting, which adds uncertainties to the already complicated economic cooperation of East Asia. Back in 2005, TPP was originally a free trade arrangement among Brunei, Chile, New Zealand, and Singapore with limited impacts on their region due to weak national strengths. On November 14, 2009, during his visit in Japan, President Obama announced the accession of US into negotiations of the TransPacific Partnership to "conclude a regional agreement that would have broad-based membership and the high standards worthy of a 21 st century trade agreement". This move tries to turn TPP into a mechanism with a wider range and higher degree of institutionalization than APEC to realize US long-term goal of establishing a Free Trade Area of the Asia Pacific (FTAAP) and Asia Pacific Community.

The pursuit of TPP is closely related to the US strategic goal of "Returning to Asia". Back in the mid- and late 1980s, the US attached equal importance to both multilateral cooperation and regional cooperation amid a slow domestic economic growth and the thriving regional cooperation around the world, making regionalism a growing important part of its foreign economic policies. In the early 1990s, regional cooperation in Asia was called "Pacific Asia" as it was conducted under 
the framework of APEC dominated by the United States. The Obama administration strives to push America to join the negotiations of the Trans-Pacific Partnership, which coincides with its strategy of "Returning to Asia". Since his taking office, Mr. Obama has re stressed the significance of the strategic position of Asia-Pacific and began to actively engage in Asia-Pacific affairs. The US secretary of state Hillary Clinton declared that "the United States is back" in Bangkok in July, 2009 marking that the US is back in Southeast Asia. Then America signed the Treaty of Amity and Cooperation (TAC) with member states of ASEAN in the same month. On November 14, 2010, Obama declared himself "America' first Pacific president" and held the first ASEAN-US summit the next day. In January of 2010, Hillary stressed that "United States is not a visiting power in Asia, but a resident power." 1 in her address about Asia-Pacific policy in Hawaii.

\section{ASEAN's Strategy of Balancing Powers}

ASEAN has to pursue the strategy of balancing powers, which means they have close economic ties with China but cooperate with the US on security issues as ASEAN is relatively small geographically with limited national strength.

The trilateral relationships among China, Japan and ROK, in particular, have maintained a unique equilibrium externally over a long period of time. In terms of political security, America and Japan are allies while China is on the opposing side. But the trilateral relationship has developed rapidly in terms of economy, and the three economies are closely interdependent on each other to a large extent. That is to say, the political relations especially strategic security relations among China, Japan and ROK are underdeveloped and separated from their economic ties. This kind of separation poses a great challenge to the trilateral relationship in an ongoing changing world. It would be difficult for these countries to realize new breakthroughs and development in economic field without the improvement in their political and security relations.

ASEAN plays a leading role as the navigator of cooperation in East Asia due to a lack of trust among China, Japan and the ROK over a long period of time. The association raised its concern of being marginalized from the region when leaders from China, Japan and ROK held a trilateral summit meeting outside the " $10+3$ " framework in December, 2008. For ASEAN, neither a deteriorated China-Japan relationship nor a closer one is what it would like to see. Therefore, as ASEAN feels threatened by China's rapid growth and its smooth cooperation with Japan and ROK, Lee Kuan Yew invited the United States to remain engaged in Asia to "balance China's military and economic might".

However, America's engagement in this region has forced countries there to take America's interest into account when participating in regional cooperation in East Asia. Therefore, regional economic integration in East Asia has been distracted and impeded, which postpones the regional cooperation, leading to the diversification of the unstructured regional cooperation in East Asia. However, this trend of

\footnotetext{
${ }^{1}$ Hillary Clinton Remarks on Regional Architecture in Asia: Principles and Priorities. Jan 12, 2010. http://www.state.gov/secretary/rm/2010/01/135090.html.
} 
diversification has not solved the fundamental problems of regional cooperation, including the scope of membership, geographical concept, leadership, ultimate goals and institutionalization of regional mechanism. Instead, the diversification has added to the complexity of regional cooperation and the negative impacts on regional stability.

\section{The Unique Feature of Regional Cooperation in East Asia}

In terms of geographical location, East Asia mainly consists of two sub-regions: Northeast Asia and Southeast Asia. Though Asia-Pacific is short for Asia and the Pacific, actually Asia-Pacific extends wider geographically and exerts great influences on the Pacific Rim including East Asia, Southern Pacific islands and the entire America. Both "East Asia" and "Asia-Pacific" have physical geographical areas and societal attributes based on economy and politics. For Americans, the United States, as a Pacific country, is naturally endowed with dual identities of both sides of the Pacific. During the Cold War, the US established diplomatic relations with most countries in East Asia through military alliances and pacts and led the regional order of East Asia where was deemed within its traditional sphere of influence. Therefore, that East Asia is included as a part of the concept of AsiaPacific is the starting point for the logic of US Asia-Pacific strategies in an American context. With the deepening of globalization, Asia-Pacific region's economic structure is more transpacific and the concepts of East Asia and AsiaPacific are closely interrelated, especially today when countries on both sides of the Pacific have formed a kind of structural dependence.

As regards the international structure, despite the fact that America's hegemony is relatively weaker now and that East Asia has shown certain degrees of independence, the structure of power in Asia has not get rid of the hub-spoke system centered on the US ${ }^{2}$ and the priority of the relations between the US and East Asia is to maintain this structure. ${ }^{3}$ To be specific, Japan and ROK (Australia included under the framework of " $10+6$ ") are US allies under the framework of " $10+3$ ", while China is deemed as a potential competitor by the United States. Therefore, East Asia is divided in terms of security issues. On the one hand, the structure of regional governance is closely related to regional political cooperation, so for East Asia, it is still on the primary phase of economic integration and has a long way to go before considering political arrangements. On the other hand, East Asia is relatively stable under the current global order led by the U.N., thus it will rely on the global framework to obtain public products of politics and security. ${ }^{4}$

In respect of each country, East Asian nations are quite diversified in size, population, the scale of economy, political system, culture and tradition. A distinctive feature of regional cooperation based on diversity is that all the participants are highly independent and exert influences to best defend their interests under the framework of cooperation. Therefore, the cooperation of East Asia

\footnotetext{
2 Yuan Peng (2009).

3 Qi Huaigao (2009).

4 Yuan Jirong (2009).
} 
displays some traits of competitive cooperation, hence joint forces of cooperation undermined. And the multi-characteristic of East Asian cooperation results in the present structure of multi-framework and also reflects the prominent feature of East Asian cooperation.

\section{Challenges Facing Regional Cooperation and Stability in East Asia}

\section{Competition Over Leadership}

It is unavoidable to talk about leadership when it comes to regional cooperation in East Asia. Diversified politics, economies, culture and systems determine the specific conditions for leadership in East Asian cooperation. Currently the mode of leadership in East Asia is the leadership led by small countries or the ASEAN mode, and in the future, possible modes are US leadership, Japan leadership, China leadership and China-Japan joint leadership, of which the first three modes belong to the mode of solo leadership, but the problem lies in that none of the three countries are qualified enough to lead East Asia by themselves. For China, it is still a rising country with relatively insufficient national strength; for the United States, it is an "outsider" - not an East Asian country geographically; while for Japan, historically, the identity of an aggressor has a negative impact on its role in East Asian cooperation. Also the chance of China-Japan joint leadership seems dim in the short term, as neither the two countries nor the key player in China-Japan relations-America, are psychologically prepared for this mode of leadership.

Cooperation in Asia starts relatively late compared with that in Europe. Over a long time after the second World War, ASEAN was the only regional cooperation mechanism that defined and integrated East Asia with great difficulty. During the same period, although Japan had tried, it failed to strengthen its cooperation with Southeast Asian countries to build a regional market for its own economic growth. ${ }^{5}$ That period was not faced with leadership competition on the whole. However, things changed when the "East Asian Miracle" became controversial due to the outbreak of financial crisis in 1997. On the one hand, the cooperation in East Asia entered an era of rapid development after the financial crisis in 1997. This kind of crisis-driven cooperation promoted the establishment of " $10+$ " mechanism with ASEAN at its core, and put the establishment of free trade zones on the agenda. On the other hand, China's rapid economic growth and active engagement in East Asian cooperation have made the US regard China as a potential competitor that threats its interests in East Asia. ${ }^{6}$ Under these circumstances competition over leadership of cooperation in East Asia seems to have realistic significance and have created real rivals. In 2006, Japan questioned the plan of establishing EAFTA under the framework of " $10+3$ " and instead promoted the extended East Asian cooperation under the framework of EAS set in 2005 . $^{7}$ Since that time, there has been controversy over the mode of East Asian cooperation and emerged competition over the

\footnotetext{
5 Hiroyuku Hoshiro Fall (2009).

6 David Shambaug (2010).

7 Zhang Yunling (2009).
} 
leadership of regional cooperation, which become the unavoidable questions in pressing ahead regional cooperation in East Asia. It is obvious that the harms of competition over leadership of East Asia have far exceeded those discussed in theory. As pointed out by professor Qing Yaqing, the deeds of some countries indicate that they have already put the competition over region leadership into practice. ${ }^{8}$

However, recently with America's intention of replacing the leadership of ASEAN, certain acts of "Returning to East Asia" have cast a shadow on the stability and development of East Asia. As the only super power in the world, the US, dictating terms in regional cooperation as well as all long performing as the leader at the international stage, has always made his voices heard with strength. And actually the current leadership of ASEAN does not display continuity; political, economic, and social development levels among ASEAN members are far from reaching the point where free trade areas and community can be established. While pushing forward the expansion of East Asia Summit will further undermine the influence of ASEAN. Pressured by the rapid rise of China and India, ASEAN has sensed their strength falling short of ambitions, thus they tries to get the US and Russia on board to build an ASEAN-centered regional framework. At the end of October, 2009, Singapore Senior Minister Lee Kuan Yew paid a visit to the US, during which he advised Barack Obama that "we need the US to maintain the balance of Asia to confront the rise of China" and warned that "If the US loses its economic leadership in Asia, the US will definitely lose its world leadership as well". 9 At the same time, Lee Kuan Yew suggested that the US should play a crucial role in the regional organization of East Asia to be built in the future. Given Lee Kuan Yew's strong political influence in Southeast Asian countries, such expressions implicitly called for Southeast Asian countries to follow closely after the US and jointly contain and counterbalance the power China. Even though subjectively ASEAN just wants to rebalance powers of East Asia through the engagement of the US, in reality opportunities are offered to the US in its competition for leadership of East Asian cooperation.

Power Distribution in East Asia

\begin{tabular}{|c|c|c|c|c|c|}
\hline Countries & US & China & Japan & ROK & ASEAN \\
\hline $\begin{array}{l}\text { Capability of influencing } \\
\text { peace and wars }\end{array}$ & Very strong & Strong & Medium & Medium/weak & Weak \\
\hline $\begin{array}{l}\text { Capability of trade, } \\
\text { investment and technology }\end{array}$ & Very strong & Strong & Strong & Medium/weak & Medium/weak \\
\hline $\begin{array}{l}\text { Representation in regional } \\
\text { mechanisms }\end{array}$ & Very strong & Strong & Medium/weak & Weak & Medium \\
\hline $\begin{array}{l}\text { Attachment to the leading } \\
\text { country }\end{array}$ & Zero & Weak & Very strong & Strong & Strong \\
\hline Recognition of status & Very strong & Strong & Medium & Weak/medium & Weak/medium \\
\hline
\end{tabular}

\footnotetext{
${ }^{8}$ Qin Yaqing (2010).

${ }^{9}$ Lee Kuan Yew (2009).
} 
As a whole, the existing international system will remain the same for some time to come and will hardly undergo any structural changes within the next decade. The US will retain its position as the only super power in the world.

\section{Barriers China, Japan and ROK Face in Multilateral Cooperation in East Asia}

At the present stage, there are still a lot of issues and barriers in the cooperation among China, Japan and ROK. Apart from the lack of trust among them caused by historical issues, territorial disputes, trade friction and systematic differences, external forces like the US also influence their relations.

Taking a view of the internal factors, political differences, exclusive nationalism, along with historical issues, territorial disputes, trade friction and systematic differences are major political barriers impeding the promotion of cooperation among the three countries. All of these internal factors lead to the lack of political trust among them, thus making it hard for them to carry out in-depth cooperation. Taking a correct attitude towards its history as an aggressor during the second world war is the first step for Japan to conduct a smoother cooperation with China, and ROK, both of which once suffered the brutal invasion and cruel ruling of Japanese imperialist. Moreover, Japan's acts of war and colonialism have left deep scars in hearts of Chinese and ROK people, such as, modification of history textbooks, visit to the Yasukuni war shrine, refusal of compensation for comfort women and denial of Nanjing Massacre. Historically, Japanese government's attitude towards the history once affected the political cooperation among China, Japan and ROK. For instance, Japan-China-ROK summit meeting on the sidelines of the ASEAN "10+3" summit scheduled to be held in 2005 was canceled due to the visit to the Yasukuni war shrine by Japan Prime Minister Koizumi. But after the "icebreaking trip" and "warm spring visit" of East Asia initiated by Japanese Prime Minister Shinzo Abe, born in the postwar period, and particularly when Summit Meeting among the People's Republic of China, the Republic of Korea and Japan outside the "10+3" summit was scheduled among China, ROK and Japan in 2008, the three countries temporarily set aside historical recognition issues and carry out all round cooperation in economic, cultural and trade areas, which have become the general trend of the promotion of strategic partnership among them. However, exclusive and antagonistic nationalism caused by territorial disputes in East Asia, trade friction and systematic differences is still possibly the major political barrier in the future, which can be exemplified by the collision of Chinese and Japanese ships near the Diaoyu Island on the East China Sea in 2010 and disputes over Liancourt Rocks between ROK and Japan in November of 2011. Territory disputes, especially those over maritime rights and interests have blocked the way towards a better cooperation among the three countries. The ownership of Diaoyu Island and demarcation of sea borders in the East China Sea are the major territory disputes between China and Japan, while disputes over the sovereignty of Liancourt Rocks have been more and more intense between ROK and Japan since the twenty-first century. On March 16, 2005, Japanese parliament passed the regulation of observing the "Takeshima Day" (Liancourt Rocks Day) on the 22 of February every year. ROK government responded by reinforcing the actual control of Liancourt Rocks 
through a series of measures, such as, complete permission for its citizens to visit Liancourt Rocks, and announced the new Japan-related principles. As a result, political and diplomatic relations between ROK and Japan have been in a stalemate, and thereby frictions and contradictions between ROK and Japan caused by the disputes over the ownership of Liancourt Rocks should be treated as the priority for concern by the two countries. Territory disputes between China and Japan and those between ROK and Japan are direct reasons for political trust crisis among the three countries. ROK, in particular, regarded as a "sandwich" country for its position between China and Japan, is sensitive to territory issues for its history of being colonized and conquered by Japan in modern times.

Apart from the above mentioned internal factors, the external manipulation and influence of the US Asia-Pacific security strategy can also account for the situation of lack of trust among China, Japan and ROK. In terms of Asia-Pacific security cooperation, the US carries out bilateral cooperation like its respective alliance with Japan and ROK instead of the mode of multilateral security cooperation under NATO. Such kind of bilateral security cooperation, manipulated by the US, leads to the distance and lack of trust among China, Japan and ROK and further America's control of security pattern of East Asia. Professor Li Xiyu from Sungkyunkwan University points out that the core of American Asia-Pacific strategy is to "divide and rule Asia" and maintain its power in this region through the establishment of bilateral alliance with Asian countries one by one. But it is quite different from what the US has done to curb the Soviet Union or later Russia through military and political alliances of NATO and European Union. Under the guidance of "divide and rule", the US will not just sit to see its own hegemonic status in East Asia undermined by the close cooperation between ROK, China and Japan, to allow the integration of East Asia in conformity with their own logic and interests. The US led "Hub-Spoke" system will exist for a long time in the future, and at the same time given the presence of bilateral alliances of Japan and ROK, America and ROK, the US probably pressures the two countries by taking advantage of the alliances with Japan and ROK, to impede the cooperation between ROK, China and Japan and in Asia. Economic dependence on the US and being politically disadvantaged positions, Japan and ROK find it difficult to resist the pressure coming from vertical alliance relation, and more than that, economic and trade dependence on the US market make the cooperation between ROK, China and Japan more likely to be under the control of the US. Just as Zbigniew Kazimierz Brzezinski, the famous American scholar of geopolitics and the former National Security Adviser, said in Asia in Transition: the Evolving Regional Order that America's farsighted Far East policies definitely can prevent the East Asian alliance, and taking various steps to thwart and curb the unity of the region becomes the fixed objective of America's policies on East Asia.

\section{China's Response}

To some degree, a series of situations emerging from current economic cooperation in East Asia have spread into the area of security: China's rapid rise prompts "the theory of chances" and "the theory of threat", exposing China to a more delicate 
and complex external environment; the US returns to Southeast Asia with the attempt to dominate the cooperation process of East Asia and Asia-Pacific; For ASEAN, the strategy of balancing powers will be more conspicuous, and cooperative policies of East Asia will be prone to be inward and conservative. American scholar David Shambaugh points out in the book Asia in Transition: the Evolving Regional Order that Asian system under the global order is undergoing great changes: old features are being redefined with new features springing up; traditional hard power elements are interacting with emerging soft power indexes. Further, he brings forward five features of current Asian system: first, the security system led by the US is still the regional security framework dominated by Asia; second, China is actively engaged in neighborhood affairs through exchanges and cooperation with neighboring countries in the fields of economy, culture, diplomacy and strategy; third, even though cooperation between China and the US in the field of bilateral, regional and global affairs are increasing, doubts and distrust still remain between them; fourth, China-Japan relation is in a stagnant state, context of which is far more complex than the "cold politics-hot economics"; Finally, regional security community and multilateral frameworks based on common grounds are arising. ${ }^{10}$ So under the circumstances of a gradually complex regional situation, what strategies should China adopt to build a favorable neighboring environment for its peaceful rise?

\section{Transforming China-US Relations from Strategic Competition into Strategic Coordination}

China could confront the competition from America with a more open mind in Asian cooperation: China should respect the political, economic and military presence of the US in East Asia, recognize the historical presence and actual interests of the US in this area and achieve its own strategic targets without undermining and challenging major interests and vested interests of the US; China should not oppose US participation in the cooperative process of East Asia, and instead, China could welcome the US to play its vigorous role and eliminate its negative impacts; Despite the fact that it is the ASEAN that decides whether the US should be admitted to the East Asia Summit, China should resist the attempt to integrate East Asia Summit, APEC and ARF into the US centered Asia-Pacific community; In terms of the advocation of TPP within the APEC, China should be cool headed, that is promoting the construction of free trade area in East Asia on the one hand and be well prepared for accession to TPP when necessary on the other; a special "Pacific relation" between East Asia and the US is the ideal goal of regional cooperation, which will transform the accomplishments of East Asian cooperation into an important channel for "China-US coordination".

In practice, "China-US coordination" could be realized on a "bilateral basis" or a "multilateral basis". In terms of the bilateral basis the two countries have upgraded the "China-US Strategic Dialogue" initiated in August of 2005 and the "China-US Strategic Economic Dialogue" initiated in December of 2006 into

${ }^{10}$ David Shambaug (2006). 
"China-US Strategic and Economic Dialogue". This kind of " $2+2$ " conference held at the level of Minister of Foreign Affairs and Minister of Finance provides a high-level channel for dialogues that cover global subjects that go beyond the bilateral basis as an significant platform for "China-US coordination". With regard to multilateral basis, there are numerous occasions for developing "China-US coordination".

\section{Intensifying Functional Cooperation and Strengthen Strategic Mutual Trust} with East Asian Countries

In recent years, basing itself on East Asia, China has begun to build the institutional framework of all-round regional cooperation and strengthen its capability of shaping geopolitics and geo-economics. The East Asian cooperation mechanism promoted by China represents new ideas of China's diplomacy. The essence of these new ideas are to develop and establish an order characterized by equality, cooperation, mutual benefits and mutual assistance on the basis of common interests in areas where China is a stake-holder, to eliminate accumulative estrangement and grudge during the constructively interactive process, and to gradually explore and gradually set down new norms of inter-state and international relations. China's aggressiveness displayed in regional cooperation improves its ability of agenda planning and promotes the sharing of China's development experience and fruits with countries in the region. World order can borrow ideas from efforts made by China to the construction of regional order. In the future, China's focus of economic cooperation in East Asia could be the strengthening of functional cooperation in all kinds of fields, the deepening of field cooperation and the solidification of each cooperative mechanism, the adoption of more open and flexible strategies in terms of key options, engagement members and institutional framework. More important, China should enhance strategic mutual trust with East Asian countries. Unlike ASEAN, East Asia has a higher degree of diversity and disparity, that is why China should formulate regional cooperative strategies featuring the well balancing of interests of its own and other countries', short-term and long-term interests as well as partial and overall interests, and explore the path and mode of community through its own development on the basis of reviewing previous policies and changes of domestic situations. Perhaps, East Asia Community is not built in the way like Europe on the basis of unified regional organization but on the regional value. So East Asian Community should become the regional cooperative system supported by several cooperative frameworks, the fundamental functions of which are to ensure the stability, safety and development of East Asia. Addressing these problems and obstacles thoroughly cannot be done overnight. Therefore, it can be foreseen that realizing the cooperation of the whole East Asia driven by the all-round cooperation among ROK, China and Japan is a long and complex process. If we want to realize a sound East Asian cooperation, a step-by-step approach should be adopted in East Asian cooperation pioneered by the cooperation among ROK, China and Japan. During this process, it is a must to establish standing offices and institutions for the smoothness and stability of economic cooperation among the three countries to realize the upgrade of functional cooperation into institutional cooperation. It is 
necessary for East Asia to treat the cooperation among ROK, China and Japan as an engine and build an East Asia community characterized by peace, friendliness and trust. In addition, for ROK, China and Japan, on the basis of overcoming the lack of trust caused by internal elements and breaking the cooperative barriers result from external elements, they should phase in development process by seeking a feasibly cooperative cut-in point and establishing the information exchange platform for regular communication to explore the depth and breadth of the cooperation among the three countries and create a sense of community in East Asia during the process.

\section{References}

Hoshiro Hiroyuku (2009) Co-prosperity again? United States foreign policy and Japan's 'first' regionalism in the 1950s. Pacific Aff 82(3):383-405

Huaigao Qi (2009) Contradiction and compatibility of China's multilateral cooperation system and American bilateral alliance system in East Asia. Intern Stud 2:11

Jirong Yuan (2009) The problems and models of the supplying of East-Asian's pubic goods and China's choice. Intern Rev 3:59

Lee Kuan Yew (2009) Losing Asia is losing world leadership for America, 2009-10-29. http://www. Zhgpl.com/crn-webapp/doc/docDetailCreate.jsp?docid=101118078

Peng Yuan (2009) Financial crisis and US economic hegemony: historical and political interpretation. Contemp Intern Relat 5:1-6

Shambaug D (2006) Asia in transition: the evolving regional order. Curr His 105(690):153-159

Shambaug D (2010) The role of changing East Asia and the United States. In: Dahui H (ed) Changing East Asia and the United States. Social Sciences Academic Press, China, p 4

Yaqing Q (2010) Regionalism in East Asia: possibilities and forms. In: Dahui H (ed) Changing East Asia and the United States. Social Sciences Academic Press, China, p 16

Yunling Z (2009) New trends of regional cooperation in East Asia. Contemp Asia-Pacific Stud 4:5 